\title{
ARTICLE
}

\section{Intermediate honeycomb ordering to trigger oxygen redox chemistry in layered battery electrode}

Benoit Mortemard de Boisse ${ }^{1,2}$, Guandong Liu', Jiangtao Ma1 , Shin-ichi Nishimura1,2, Sai-Cheong Chung ${ }^{1,2}$, Hisao Kiuchi ${ }^{3}$, Yoshihisa Harada ${ }^{4,5}$, Jun Kikkawa ${ }^{6}$, Yoshio Kobayashi ${ }^{7,8}$, Masashi Okubo ${ }^{1,2}$ \& Atsuo Yamada ${ }^{1,2}$

Sodium-ion batteries are attractive energy storage media owing to the abundance of sodium, but the low capacities of available cathode materials make them impractical. Sodium-excess metal oxides $\mathrm{Na}_{2} \mathrm{MO}_{3}$ (M: transition metal) are appealing cathode materials that may realize large capacities through additional oxygen redox reaction. However, the general strategies for enhancing the capacity of $\mathrm{Na}_{2} \mathrm{MO}_{3}$ are poorly established. Here using two polymorphs of $\mathrm{Na}_{2} \mathrm{RuO}_{3}$, we demonstrate the critical role of honeycomb-type cation ordering in $\mathrm{Na}_{2} \mathrm{MO}_{3}$. Ordered $\mathrm{Na}_{2} \mathrm{RuO}_{3}$ with honeycomb-ordered $\left[\mathrm{Na}_{1 / 3} \mathrm{Ru}_{2 / 3}\right] \mathrm{O}_{2}$ slabs delivers a capacity of $180 \mathrm{mAhg}^{-1}$ (1.3-electron reaction), whereas disordered $\mathrm{Na}_{2} \mathrm{RuO}_{3}$ only delivers $135 \mathrm{mAhg}^{-1}$ (1.0-electron reaction). We clarify that the large extra capacity of ordered $\mathrm{Na}_{2} \mathrm{RuO}_{3}$ is enabled by a spontaneously ordered intermediate $\mathrm{Na}_{1} \mathrm{RuO}_{3}$ phase with ilmenite O1 structure, which induces frontier orbital reorganization to trigger the oxygen redox reaction, unveiling a general requisite for the stable oxygen redox reaction in high-capacity $\mathrm{Na}_{2} \mathrm{MO}_{3}$ cathodes.

\footnotetext{
${ }^{1}$ Department of Chemical System Engineering, School of Engineering, The University of Tokyo, Hongo 7-3-1, Bunkyo-ku, Tokyo 113-8656, Japan. ${ }^{2}$ Elements Strategy Initiative for Catalysts \& Batteries (ESICB), Kyoto University, Nishikyo-ku, Kyoto 615-8245, Japan. ${ }^{3}$ Department of Applied Chemistry, School of Engineering, The University of Tokyo, Bunkyo-ku, Tokyo 113-8656, Japan. ${ }^{4}$ Institute for Solid State Physics, The University of Tokyo, Kashiwa, Chiba 277-8581, Japan. ${ }^{5}$ Synchrotron Radiation Research Organization, The University of Tokyo, Tatsuno, Hyogo 679-5165, Japan. ${ }^{6}$ Advanced Key Technologies Division, National Institute for Materials Science, Tsukuba, Ibaraki 305-0044, Japan. ${ }^{7}$ Department of Engineering Science, The University of Electro-Communications, Chofu, Tokyo 182-8585, Japan. ${ }^{8}$ RIKEN Nishina Center for Accelerator-Based Science, RIKEN, Wako, Saitame 351-0198, Japan. Correspondence and requests for materials should be addressed to A.Y. (email: yamada@chemsys.t.u-tokyo.ac.jp).
} 
i-ion batteries power almost all of today's portable electronics and their ability to store energy is increasingly important for large-scale applications such as electric vehicles and power grids. However, Li resources are limited and unevenly distributed geographically; hence, alternatives need to be found. Na-ion batteries have garnered great attention as candidates for large-scale applications owing to the abundance and low cost of sodium. Accordingly, Na-ion (de)intercalation compounds have been explored intensively ${ }^{1-8}$.

Among the various positive electrode materials that have been investigated, layered transition metal oxides $\mathrm{NaMO}_{2} \quad(\mathrm{M}=$ transition metal) are considered to be the most promising ${ }^{3,9-13}$, in part owing to their large theoretical capacities and the simple analogies from the successful application of $\mathrm{LiMO}_{2}$ in Li-ion battery systems. However, the stably cyclable capacity of $\mathrm{NaMO}_{2}$ is too small for practical use because deintercalation of a large amount of $\mathrm{Na}$ ions from the $\mathrm{Na}$ layer between the $\mathrm{MO}_{2}$ slabs usually causes irreversible structural changes ${ }^{14,15}$.

Replacing $\mathrm{M}$ atoms in the $\mathrm{MO}_{2}$ slab with $\mathrm{Na}$ (for example, $\mathrm{Na}\left[\mathrm{Na}_{1 / 3} \mathrm{M}_{2 / 3}\right] \mathrm{O}_{2}$ or $\left.\mathrm{Na}_{2} \mathrm{MO}_{3}\right)$ is an appealing strategy to suppress these structural changes over a wider compositional range. The $\left[\mathrm{Na}_{1 / 3} \mathrm{M}_{2 / 3}\right] \mathrm{O}_{2}$ slabs supply additional $\mathrm{Na}$ ions, thereby increasing the reversible capacity while suppressing the over-deintercalation of $\mathrm{Na}$ ions from the $\mathrm{Na}$ layer. This ' $A_{2-x} \mathrm{MO}_{3}$ ' strategy has already been adopted in many lithium systems such as $\mathrm{Li}_{2} \mathrm{MnO}_{3}-\mathrm{LiMO}_{2}$ and $\mathrm{Li}_{2} \mathrm{RuO}_{3}$, in which enhanced capacities exceeding a $\mathrm{M}^{4+} / \mathrm{M}^{3+}$ one-electron reaction have been achieved through additional oxygen redox contribution $^{16-18}$.

In our previous work, we applied this strategy to sodium systems, using a model compound, $\mathrm{Na}_{2} \mathrm{RuO}_{3} \quad\left(\mathrm{Na}\left[\mathrm{Na}_{1 / 3} \mathrm{Ru}_{2 / 3}\right] \mathrm{O}_{2}\right)^{19}$. However, despite the presence of $\left[\mathrm{Na}_{1 / 3} \mathrm{Ru}_{2 / 3}\right] \mathrm{O}_{2}$ slabs, $\mathrm{Na}_{2} \mathrm{RuO}_{3}$ delivered a modest capacity of $135 \mathrm{mAhg}^{-1}$, limited to the $\mathrm{Ru}^{5+} / \mathrm{Ru}^{4+}$ one-electron reaction. In contrast, Rozier et al. ${ }^{20}$ very recently reported that $\mathrm{Na}_{2} \mathrm{RuO}_{3}$ can deliver a capacity greatly exceeding that of the $\mathrm{Ru}^{5+} / \mathrm{Ru}^{4+}$ one-electron reaction. At present, the discrepancy between the reported electrochemical properties is an open question. More generally, the requisite conditions for successful application of the ' $A_{2}{ }_{x} \mathrm{MO}_{3}$ ' strategy for large-capacity sodium systems are poorly understood.

Here we demonstrate that a highly stabilized intermediate phase with honeycomb-type cation ordering in the $\left[\mathrm{Na}_{1 / 3} \mathrm{M}_{2 / 3}\right] \mathrm{O}_{2}$ slab is critical for the effective use of the ' $A_{2}-{ }_{x} \mathrm{MO}_{3}$ ' strategy, by comparing two polymorphs of $\mathrm{Na}_{2} \mathrm{RuO}_{3}$; namely, 'ordered' $\mathrm{Na}_{2} \mathrm{RuO}_{3}$ with honeycomb-ordered $\left[\mathrm{Na}_{1 / 3} \mathrm{M}_{2 / 3}\right] \mathrm{O}_{2}$ slabs and 'disordered' $\mathrm{Na}_{2} \mathrm{RuO}_{3}$ with randomly distributed $\left[\mathrm{Na}_{1 / 3} \mathrm{M}_{2 / 3}\right] \mathrm{O}_{2}$ slabs (Fig. 1).

\section{Results}

Structural characterization of $\mathrm{Na}_{2} \mathrm{RuO}_{3}$. Ordered $\mathrm{Na}_{2} \mathrm{RuO}_{3}$ (hereafter denoted $\mathrm{O}-\mathrm{Na}_{2} \mathrm{RuO}_{3}$ ) was synthesized by a thermal decomposition method, in which $\mathrm{Na}_{2} \mathrm{RuO}_{4}$ was annealed at $850^{\circ} \mathrm{C}$ for $48 \mathrm{~h}$ under an $\mathrm{Ar}$ atmosphere ${ }^{21}$. Disordered $\mathrm{Na}_{2} \mathrm{RuO}_{3}$ (hereafter denoted $\mathrm{D}-\mathrm{Na}_{2} \mathrm{RuO}_{3}$ ) was synthesized for comparison according to our previously reported procedure ${ }^{19}$. The ${ }^{99} \mathrm{Ru}$ Mössbauer spectra of both compounds (insets in Fig. 2a,b) show a singlet absorption peak with an isomer shift around $-0.3 \mathrm{mms}^{-1}$, which is a typical value for $\mathrm{Ru}^{4+}$ (for example, $-0.25 \mathrm{~mm} \mathrm{~s}^{-1}$ for $\mathrm{Y}_{2} \mathrm{Ru}_{2} \mathrm{O}_{7}$ and $-0.33 \mathrm{~mm} \mathrm{~s}^{-1}$ for $\left.\mathrm{SrRuO}_{3}\right)^{22}$, suggesting successful formation of stoichiometric $\mathrm{Na}_{2} \mathrm{RuO}_{3}$ compositions from both syntheses. The synchrotron X-ray diffraction (XRD) pattern of $\mathrm{D}-\mathrm{Na}_{2} \mathrm{RuO}_{3}$ (Fig. 2a) is fully indexed to the O3 structure $(R \overline{3} m$ space group, $a=3.0969(3) \AA$ and $c=15.970(2) \AA)$; all diffraction peaks are well-fitted by Rietveld refinement with a structural model in which $\mathrm{Na}$ and $\mathrm{Ru}$

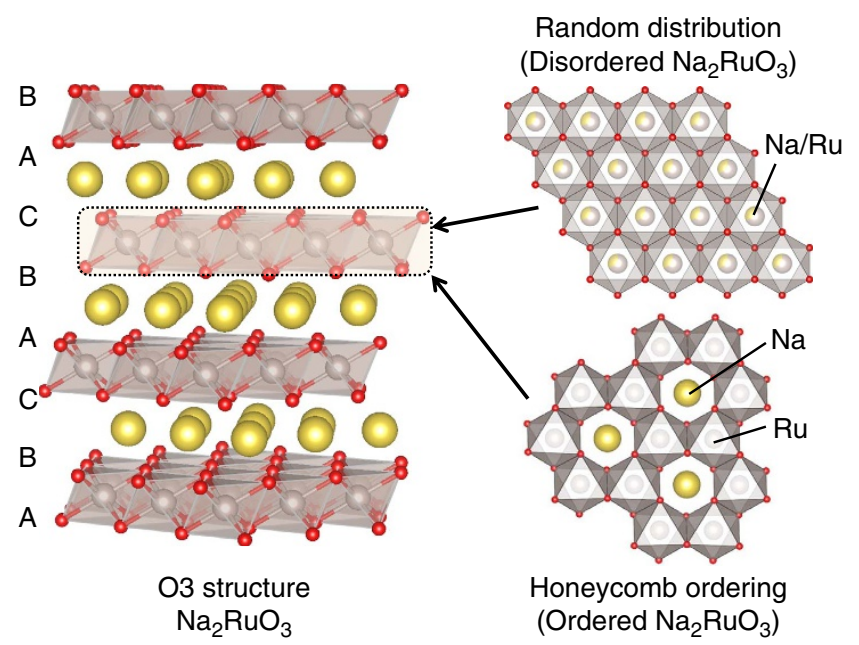

Figure 1 | Structure of ordered and disordered $\mathrm{Na}_{2} \mathrm{RuO}_{3}$. Oxide ions (red) stack in the manner of $A B C A B C$ while both $\mathrm{Na}$ (yellow) and $\mathrm{Ru}$ (grey) occupy octahedral sites for both $\mathrm{Na}_{2} \mathrm{RuO}_{3}$. Ordered $\mathrm{Na}_{2} \mathrm{RuO}_{3}$ has the honeycomb-type cation ordering in the $\left[\mathrm{Na}_{1 / 3} \mathrm{Ru}_{2 / 3}\right] \mathrm{O}_{2}$ slab. Disordered $\mathrm{Na}_{2} \mathrm{RuO}_{3}$ has the randomly distributed $\left[\mathrm{Na}_{1 / 3} \mathrm{Ru}_{2 / 3}\right] \mathrm{O}_{2}$ slab.

are randomly distributed in the $\left[\mathrm{Na}_{1 / 3} \mathrm{Ru}_{2 / 3}\right] \mathrm{O}_{2}$ slabs (Fig. 1 and Supplementary Table 1). $\mathrm{Na}$ in the Na layer occupies octahedral sites and the oxide ions are stacked in an ABCABC arrangement $(\mathrm{O} 3 \text { structure })^{23}$. The selected area electron diffraction (SAED) pattern along the $[001]_{\text {hex }}$ zone axis (Fig. 2c) shows diffraction spots fully indexed by the $R \overline{3} m$ model with disordered $\left[\mathrm{Na}_{1 / 3} \mathrm{Ru}_{2 / 3}\right] \mathrm{O}_{2}$ slabs.

The synchrotron XRD pattern of $\mathrm{O}-\mathrm{Na}_{2} \mathrm{RuO}_{3}$ (Fig. $2 \mathrm{~b}$ and Supplementary Table 1) is similar to that of $\mathrm{D}-\mathrm{Na}_{2} \mathrm{RuO}_{3}$ and is almost fitted by Rietveld refinement in the $R \overline{3} m$ space group $(a=3.1195(5) \AA$ and $c=15.989(4) \AA)$ assuming disordered $\left[\mathrm{Na}_{1 / 3} \mathrm{Ru}_{2 / 3}\right] \mathrm{O}_{2}$ slabs. However, diffuse scatterings remain, as highlighted by the black arrows in Fig. 2b. Similar characteristics have been reported for many $A_{2} \mathrm{MO}_{3} \quad(A=\mathrm{Li}, \mathrm{Na}$ and $\mathrm{M}=$ transition metal(s)) materials, and usually arise from honeycomb ordering in the $\mathrm{MO}_{2}$ slabs ${ }^{16,17,20}$. Indeed, the SAED pattern along the $[001]_{\text {hex }}$ zone axis (Fig. 2d) shows many extra diffraction spots, which are not predicted using the standard $R \overline{3} m$ model with disordered $\left[\mathrm{Na}_{1 / 3} \mathrm{Ru}_{2 / 3}\right] \mathrm{O}_{2}$ slabs. These spots can be indexed to a $\sqrt{3} a_{\text {hex }} \times \sqrt{3} b_{\text {hex }}$ supercell arising from the honeycomb ordering of $\mathrm{Na}$ and $\mathrm{Ru}$ in the $\left[\mathrm{Na}_{1 / 3} \mathrm{Ru}_{2 / 3}\right] \mathrm{O}_{2}$ slabs (Fig. 1). In contrast, the SAED pattern along the $[110]_{\text {hex }}$ zone axis (Fig. 2e) shows extra streaks along [001 $]_{\text {hex. This }}$ feature is characteristic of stacking faults in honeycomb-ordered $\left[A_{1 / 3} \mathrm{M}_{2 / 3}\right] \mathrm{O}_{2}$ slabs along the $c_{\text {hex }}$ direction, explaining the diffusive nature of the superstructure reflections in Fig. $2 \mathrm{~b}$ (ref. 24).

Electrochemical properties of $\mathrm{Na}_{2} \mathrm{RuO}_{3}$. Having demonstrated the differences between $\mathrm{O}$ - and $\mathrm{D}-\mathrm{Na}_{2} \mathrm{RuO}_{3}$ in terms of the inplane ordering and stacking sequences of the $\left[\mathrm{Na}_{1 / 3} \mathrm{Ru}_{2 / 3}\right] \mathrm{O}_{2}$ slabs, the $\mathrm{Na}^{+}$(de)intercalation properties of both materials were studied to clarify the influence of the honeycomb ordering. Figure 3a,b shows the charge-discharge curves measured between 1.5 and $4.0 \mathrm{~V}$ versus $\mathrm{Na} / \mathrm{Na}^{+}$at $30 \mathrm{mAg}^{-1}$ (a rate of $\sim \mathrm{C} / 5$ ). Here charging is an anodic process ( $\mathrm{Na}$ deintercalation) and discharging is a cathodic process ( $\mathrm{Na}$ intercalation). $\mathrm{D}-\mathrm{Na}_{2} \mathrm{RuO}_{3}$ (Fig. 3a) delivers a reversible capacity of $135 \mathrm{mAhg}^{-1}$, corresponding to (de)intercalation of $1.0 \mathrm{Na}^{+}$, which is consistent with our previous report ${ }^{19}$. In contrast, the reversible capacity of 

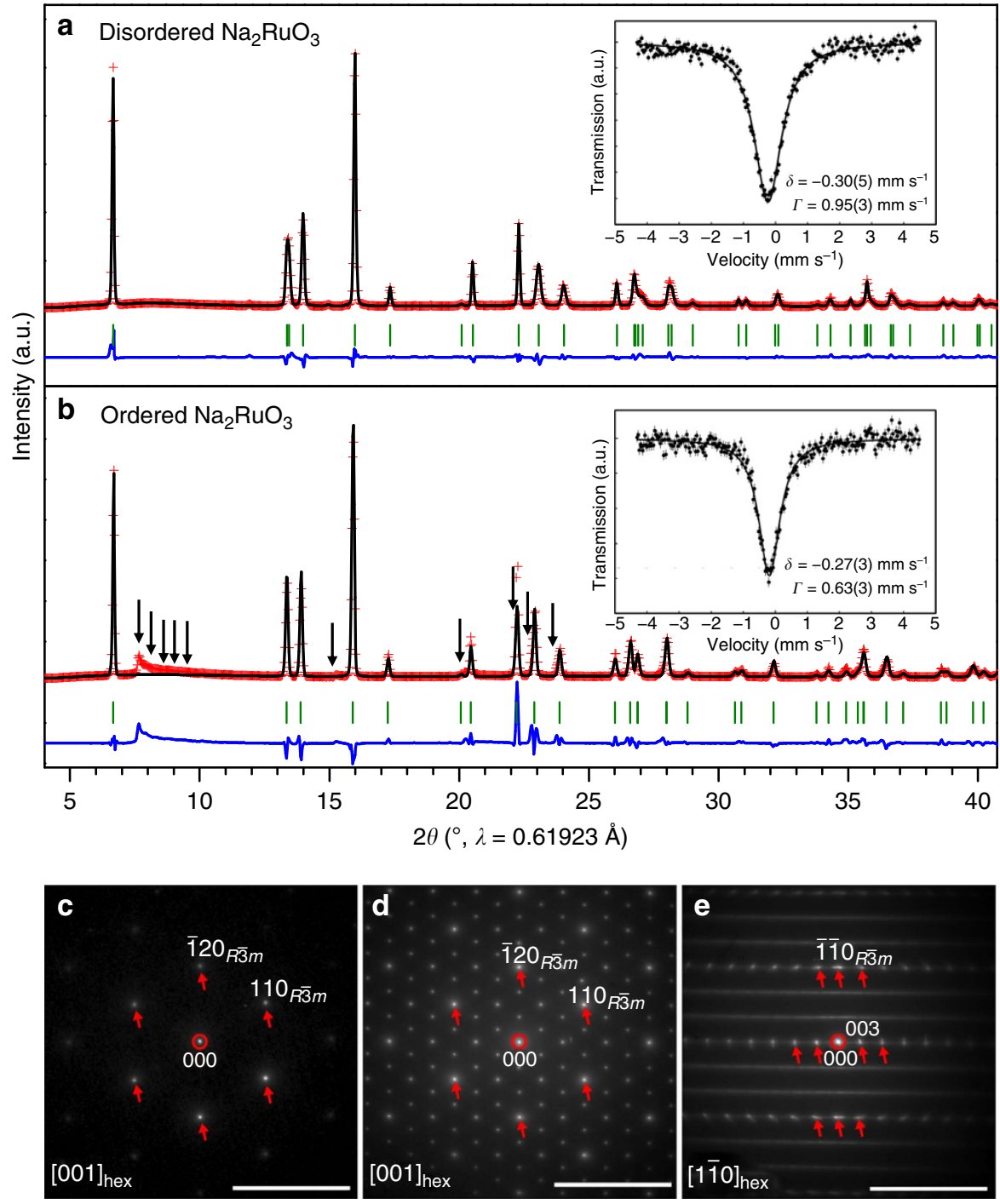

Figure 2 | Structural characterization of disordered and ordered $\mathbf{N a}_{\mathbf{2}} \mathbf{R} \mathbf{\mathbf { O } _ { 3 }}$. Observed and calculated (Rietveld method) synchrotron $\mathrm{X}$-ray diffraction patterns for (a) disordered and (b) ordered $\mathrm{Na}_{2} \mathrm{RuO}_{3}$. Red crosses: experimental, black line: calculated, blue line: difference and green bars: Bragg positions. The black arrows in $\mathbf{b}$ indicate the superstructure peaks that were not considered for the refinement. Insets of $\mathbf{a}, \mathbf{b}$ correspond to the ${ }^{99}$ Ru Mössbauer spectra recorded at $4.2 \mathrm{~K}$ for both pristine materials. Vertical error bars represent $1 \sigma$ s.d. of counting statistics. Selected area electron diffraction (SAED) patterns in the (c) [001] hex zone axes of disordered $\mathrm{Na}_{2} \mathrm{RuO}_{3}$, and in the (d) [001] hex and (e) [110] hex zone axes of ordered $\mathrm{Na}_{2} \mathrm{RuO} \mathrm{O}_{3}$. The red circles and arrows, respectively, indicate the central and fundamental diffraction spots, which are common to disordered $\mathrm{Na}_{2} \mathrm{RuO}_{3}$. Un-marked diffraction spots in between correspond to superstructure peaks. Scale bars, $10 \mathrm{~nm}^{-1}$.

$\mathrm{O}-\mathrm{Na}_{2} \mathrm{RuO}_{3}$ exceeds $180 \mathrm{mAhg}^{-1}$, indicating reversible (de)intercalation of $1.3 \mathrm{Na}^{+}$, beyond a $\mathrm{Ru}^{5+} / \mathrm{Ru}^{4+}$ oneelectron redox process. This behaviour is in agreement with that of $\mathrm{Na}_{2} \mathrm{RuO}_{3}$ reported by Rozier et al. ${ }^{20}$. Importantly, the voltage profile of $\mathrm{O}-\mathrm{Na}_{2} \mathrm{RuO}_{3}$ significantly differs from the S-shaped voltage profile of $\mathrm{D}-\mathrm{Na}_{2} \mathrm{RuO}_{3}$. O-Na $\mathrm{NuO}_{3}(0.7 \leq x \leq 2)$ exhibits a staircase-like charge profile with a first voltage plateau around $2.5 \mathrm{~V}$ for $1.0 \leq x \leq 2.0$ and a second voltage plateau around $3.6 \mathrm{~V}$ for $0.7 \leq x \leq 1.0$; the second voltage plateau is related to the extra capacity of $\mathrm{O}-\mathrm{Na}_{2} \mathrm{RuO}_{3}$, which exceeds that of the $\mathrm{Ru}^{5+} / \mathrm{Ru}^{4+}$ one-electron reaction. Although the plateau at $3.6 \mathrm{~V}$ shows gradual narrowing with repeating the cycles presumably due to slight loss of the crystallinity (Supplementary Fig. 1a,b), O- $\mathrm{Na}_{2} \mathrm{RuO}_{3}$ shows excellent capacity retention of $160 \mathrm{mAhg}^{-1}$ after 50 cycles (Fig. 3c), which indicates the remarkable stability of the redox processes that contribute to the increased capacity. Indeed, the voltage plateau around $3.6 \mathrm{~V}$ is clearly observed for every charge process, suggesting occurrence of the accumulative oxygen redox reaction (Supplementary Fig. $1 c, d)^{18}$. Therefore, the available capacity significantly exceeds one-electron redox reaction for $\mathrm{O}-\mathrm{Na}_{2} \mathrm{RuO}_{3}$ even after 50 cycles. It is surprising that the in-plane honeycomb-type cation ordering in $\mathrm{O}-\mathrm{Na}_{2} \mathrm{RuO}_{3}$ is solely responsible for the drastic changes in the electrochemical properties that results in $30 \%$ higher capacity. To the best of our knowledge, this is the first demonstration of the critical role of honeycomb-type cation ordering in $\left[A_{1 / 3} \mathrm{M}_{2 / 3}\right] \mathrm{O}_{2}$ slabs in determining the primary electrochemical properties.

Structural change during (de)sodiation. To clarify the reaction mechanisms in $\mathrm{Na}_{2} \mathrm{RuO}_{3}$, we studied the structural changes of $\mathrm{D}-\mathrm{Na}_{2} \mathrm{RuO}_{3}$ and $\mathrm{O}-\mathrm{Na}_{2} \mathrm{RuO}_{3}$ during cycling (Fig. 4a-d). As reported previously ${ }^{19}$ and further supported by ex situ XRD 

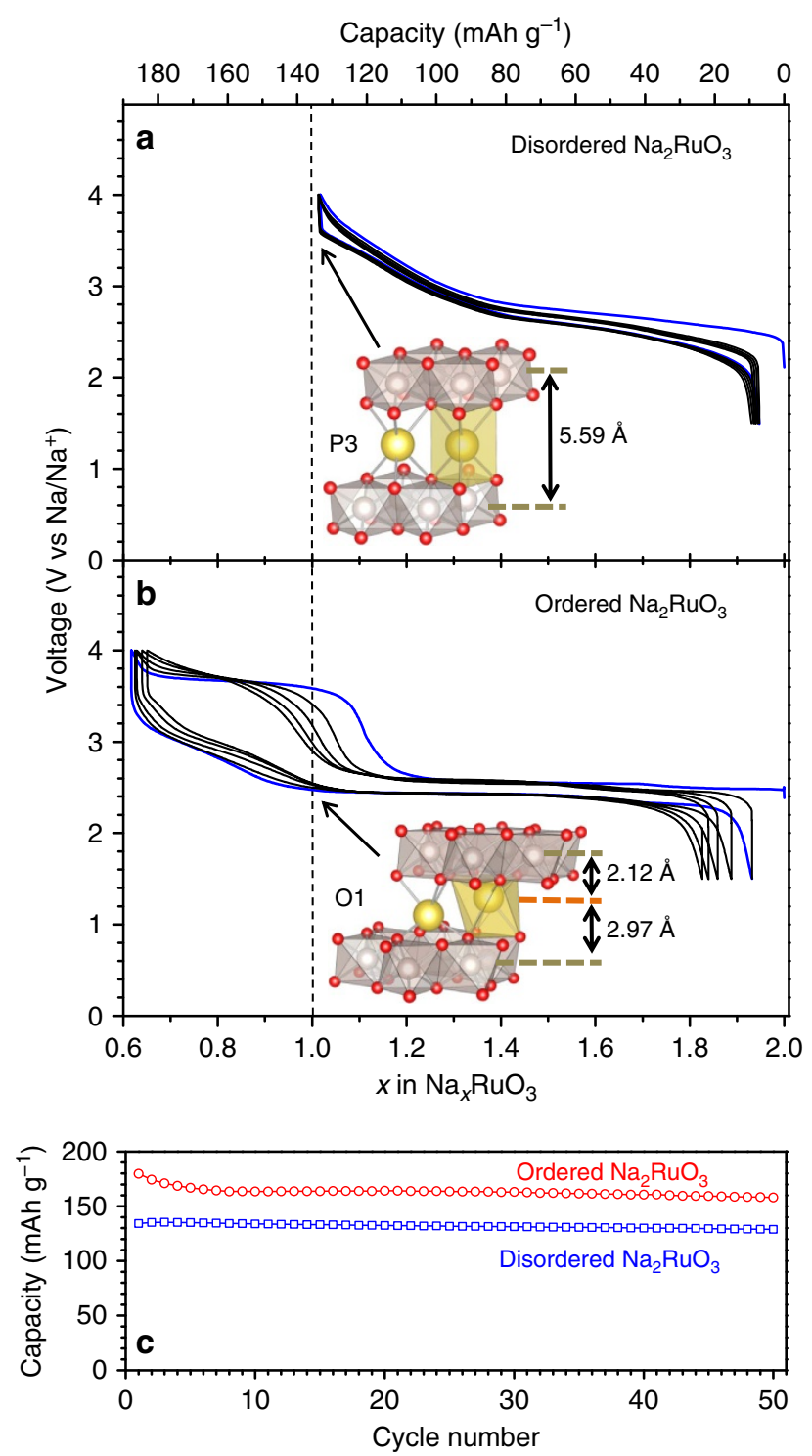

Figure 3 | Electrochemical properties of disordered and ordered $\mathbf{N a}_{\mathbf{2}} \mathbf{R} \mathbf{u} \mathbf{O}_{\mathbf{3}}$. Galvanostatic cycling curves recorded at $30 \mathrm{~mA} \mathrm{~g}^{-1}$ for (a) disordered and (b) ordered $\mathrm{Na}_{2} \mathrm{RuO}_{3}$ with the first cycle highlighted in blue. Insets show the coordination environment of $\mathrm{Na}$ at $x=1.0$ for each phase. (c) Capacity retentions for (blue squares) disordered and (red circles) ordered $\mathrm{Na}_{2} \mathrm{RuO}_{3}$.

patterns (Supplementary Fig. 2), $\mathrm{D}-\mathrm{Na}_{x} \mathrm{RuO}_{3}$ undergoes a structural change from $\mathrm{O} 3$ to $\mathrm{P} 3$ (with $\mathrm{Na}$ in prismatic sites owing to the ABBCCA oxide-ion stacking) on charging ${ }^{23}$. This $\mathrm{O} 3 \rightarrow \mathrm{P} 3$ transition is commonly observed in $\mathrm{O} 3-\mathrm{NaMO}_{2}$ materials through gliding of the $\left[\mathrm{Na}_{1 / 3} \mathrm{Ru}_{2 / 3}\right] \mathrm{O}_{2}$ slabs from ABCABC (O3) to ABBCCA (P3) stacking ${ }^{9,25}$. The synchrotron XRD pattern of the charged state $\left(\mathrm{D}-\mathrm{Na}_{1} \mathrm{RuO}_{3}\right.$; Supplementary Fig. 3 and Supplementary Table 2) is fully fitted by the Rietveld refinement assuming a P3 structure $(R \overline{3} m$ space group, $a=2.927(2) \AA$ and $c=16.774(12) \AA$ ), in which Na ions in the $\mathrm{Na}$ layer are located in prismatic sites (inset in Fig. 3a). The interlayer distance is significantly increased from 5.323(1) $\AA$ $(x=2)$ to $5.591(4) \AA(x=1)$ because of the high aspect ratio of the prismatic Na sites in the P3 structure (Fig. 4a).

It should be emphasized that $\mathrm{O}-\mathrm{Na}_{2} \mathrm{RuO}_{3}$ exhibits a completely different structural evolution from $\mathrm{D}-\mathrm{Na}_{2} \mathrm{RuO}_{3}$ on charging. The in situ and ex situ XRD patterns of $\mathrm{O}-\mathrm{Na}_{2} \mathrm{RuO}_{3}$ (Supplementary Figs 4 and 5) at the first plateau show that an intermediate phase ' $\mathrm{X}$ ' with an unknown structure (presumably a P-type phase based on the interlayer distance of around $5.5 \AA$ ) appears during the initial stages of the desodiation, and that the $\mathrm{O} 3$ phase is eventually transformed to a new phase at $x=1$ with an extremely short interlayer distance of around $5.2 \AA$ (Fig. 4a). These complex equilibria among the $\mathrm{O} 3, \mathrm{X}$ and $\mathrm{O} 1$ phases are responsible for the long voltage plateau observed in the $1 \leq x \leq 2$ composition range of $\mathrm{O}-\mathrm{Na}_{x} \mathrm{RuO}_{3}$. On charging, the diffuse scatterings of the superstructure gradually disappear, while new, well-resolved peaks appear (Fig. 4d). The well-resolved character of the new superstructure reflections suggest that the disordered stacking of the honeycomb lattice is spontaneously adjusted towards the ordered state during electrochemical desodiation. The Rietveld refinement and SAED pattern of $\mathrm{O}-\mathrm{Na}_{1} \mathrm{RuO}_{3}$ (Fig. 4b,c and Supplementary Tables 2 and 3 ) confirm that the $\left[\mathrm{Na}_{1 / 3} \mathrm{Ru}_{2 / 3}\right] \mathrm{O}_{2}$ layers maintain the original honeycomb-type in-plane ordering. As shown in Fig. 4b, the ABCABC stacking sequence of oxygen is transformed to an $\mathrm{ABAB}$ sequence, in which $\mathrm{Na}$ in the $\mathrm{Na}$ layer occupies octahedral sites (O1 structure; inset in Fig. 3b). This ordered structure is isomorphic with the ilmenite $\mathrm{FeTiO}_{3}$-type structure $^{26}$.

In the refined structure of $\mathrm{O}-\mathrm{Na}_{1} \mathrm{RuO}_{3}(R \overline{3}$ space group, $a=5.2492(1) \AA$ and $c=15.6201(6) \AA)$, the $\mathrm{Na}$ site in the $\left[\mathrm{Na}_{1 / 3} \mathrm{Ru}_{2 / 3}\right] \mathrm{O}_{2}$ slabs is vacant, which means $\mathrm{Na}$ was extracted from the $\left[\mathrm{Na}_{1 / 3} \mathrm{Ru}_{2 / 3}\right] \mathrm{O}_{2}$ slabs prior to the $\mathrm{Na}$ layers. In this very unique, stable intermediate ilmenite-type $\mathrm{Na}_{1} \mathrm{RuO}_{3}$, all $\mathrm{NaO}_{6}$ octahedra in the $\mathrm{Na}$ layer share faces with $\mathrm{a} \mathrm{RuO}_{6}$ octahedron and a ' $\square \mathrm{O}_{6}$ ' octahedron of the adjacent $\left[\square_{1 / 3} \mathrm{Ru}_{2 / 3}\right] \mathrm{O}_{2}$ slabs ( $\square$ : Na vacancy). As shown in Fig. 4a, the interlayer distance of O- $\mathrm{Na}_{1} \mathrm{RuO}_{3}(5.2067(2) \AA)$ is much shorter than that of $\mathrm{D}-\mathrm{Na}_{1} \mathrm{RuO}_{3}$ (5.591(4) $\AA$ ) as a result of substantial displacement of $\mathrm{Na}$ in the $\mathrm{Na}$ layer towards $\square \mathrm{O}_{6}$ octahedra by Coulombic attraction (Fig. 4b). Importantly, the $\mathrm{RuO}_{6}$ octahedron is strongly distorted: the shortest neighbouring O-O distance is $2.580(4) \AA$, whereas the longest is 3.080(6) A (Fig. 5 and Supplementary Table 3).

The ilmenite structure of $\mathrm{O}-\mathrm{Na}_{1} \mathrm{RuO}_{3}$ is stabilized by the following mechanisms: (1) the ordered $\mathrm{Na}$ arrangement minimizes $\mathrm{Na}^{+}{ }_{-} \mathrm{Na}^{+}$repulsion; (2) the $\mathrm{Na}$ vacancy $\square$ in the $\left[\square_{1 / 3} \mathrm{Ru}_{2 / 3}\right] \mathrm{O}_{2}$ slab strongly attracts $\mathrm{Na}$ ions in the face-sharing octahedra in adjacent $\mathrm{Na}$ layers; (3) the ordered and displaced arrangement of $\mathrm{Na}$ ions minimizes $\mathrm{Ru}^{5+}-\mathrm{Na}^{+}$repulsive interactions; and (4) the cooperative distortion of the $\mathrm{RuO}_{6}$ octahedra can minimize the total strain energy in the ordered honeycomb lattice. All these mechanisms lead to the formation of the ilmenite phase with well-ordered stacking of the honeycomb lattices.

On discharge, in situ XRD patterns (Supplementary Fig. 4) prove that the phase transformation is almost reversible except for a small asymmetry, that is, the appearance of the $\mathrm{X}$ phase only at charge. Presumably, this parasitic asymmetric behaviour is observed under non-equilibrium conditions such as the microscale heterogeneity.

Electronic structure of $\mathrm{Na}_{2}-{ }_{x} \mathbf{R u O}_{3}$. After the $\mathrm{O} 3 \rightarrow \mathrm{O} 1$ transition, $\mathrm{O}-\mathrm{Na}_{2} \mathrm{RuO}_{3}$ delivers additional capacity, exceeding that of the $\mathrm{Ru}^{5+} / \mathrm{Ru}^{4+}$ one-electron reaction at the higher voltage plateau of around $3.7 \mathrm{~V}$. To clarify the overall redox mechanism in $\mathrm{O}-\mathrm{Na}_{2} \mathrm{RuO}_{3}$, we conducted $\mathrm{Ru} L_{3}$-edge and oxygen $K$-edge $\mathrm{X}$-ray absorption spectroscopy (XAS) in the partial fluorescence yield mode at various charge depths (Fig. 6, Supplementary Figs 6 and 7 ). The $\mathrm{Ru} L_{3}$-edge XAS directly probes the $4 d$ orbitals through the Laporte-allowed $2 p \rightarrow 4 d$ transition $^{27}$. Furthermore, because the $\mathrm{O} 2 p$ orbital strongly hybridizes with the $\mathrm{Ru} 4 d$ 

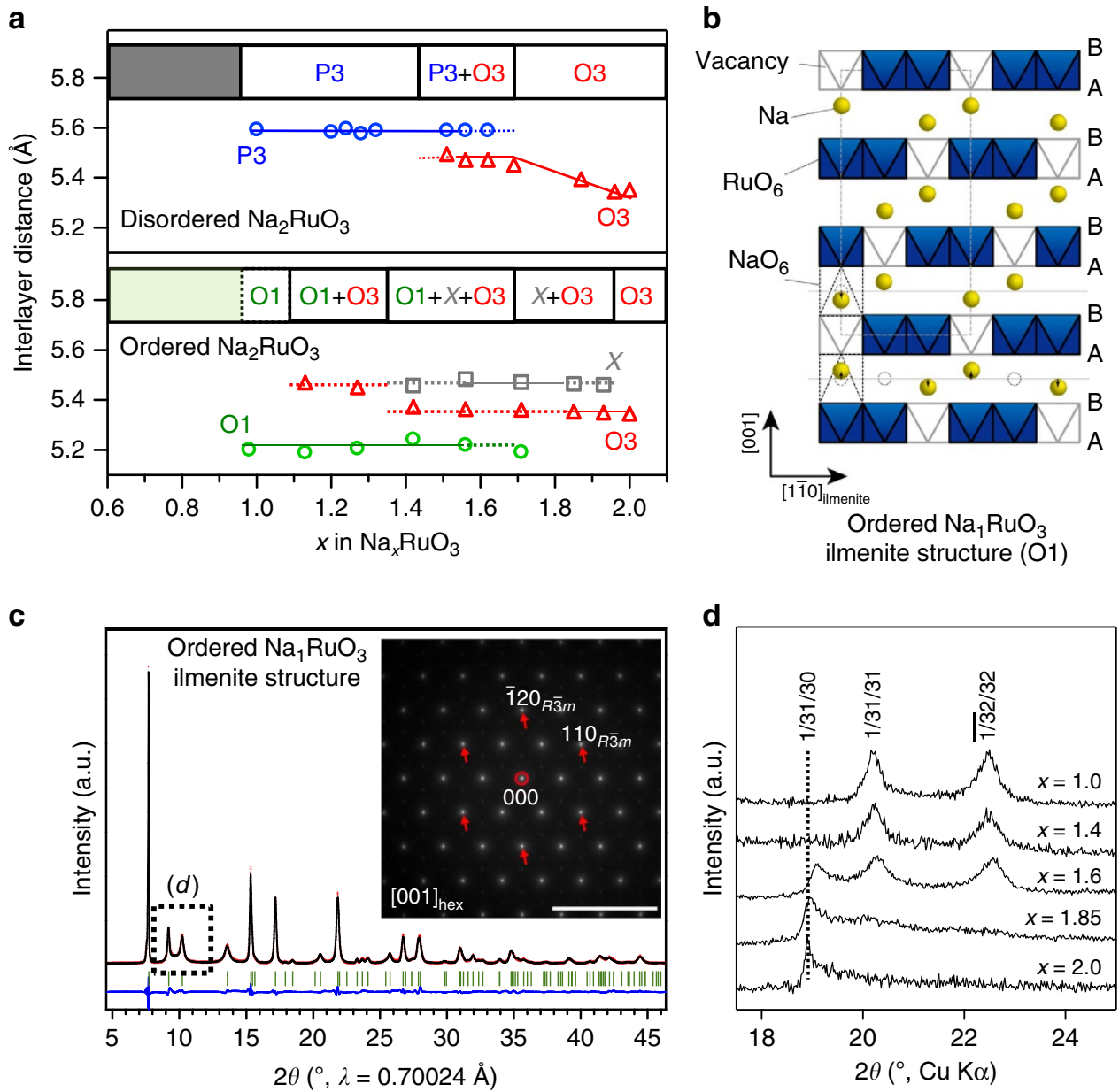

Figure 4 | Structural changes of disordered and ordered $\mathbf{N a}_{2} \mathbf{R u O}_{3}$ during charge. (a) Interlayer distance of the different phases involved on desodiation as a function of $x$ in disordered and ordered $\mathrm{Na}_{x} \mathrm{RuO}_{3}$. (b) Crystal structure of ilmenite-type $\mathrm{Na}_{1} \mathrm{RuO}_{3}$. All $\mathrm{Na}$ ions displace cooperatively towards $\mathrm{Na}$ vacancies in the honeycomb planes. (c) Observed and calculated (Rietveld method) synchrotron X-ray diffraction patterns for ordered $\mathrm{Na}_{1} \mathrm{RuO}_{3}$. Red crosses: experimental, black line: calculated, blue line: difference and green bars: Bragg positions. The inset shows the selected area electron diffraction (SAED) pattern for ilmenite-type $\mathrm{Na}_{1} \mathrm{RuO}_{3}$. Scale bar, $10 \mathrm{~nm}^{-1}$ (d) Ex situ XRD patterns showing the evolution of the superstructure peaks for ordered $\mathrm{Na}_{x} \mathrm{RuO}_{3}$ on charge.

orbital, oxygen $K$-edge XAS can be used to monitor the hole created on the $\mathrm{O} 2 p$ and $\mathrm{Ru} 4 d$ orbitals on charging ${ }^{28}$. Note that the probing depth of the partial fluorescence yield mode is about $100 \mathrm{~nm}$; hence, the spectra are bulk sensitive ${ }^{29}$.

The $\mathrm{Ru} L_{3}$-edge spectrum for pristine $\mathrm{O}-\mathrm{Na}_{2} \mathrm{RuO}_{3}\left(t_{2 \mathrm{~g}}^{4} e_{\mathrm{g}}^{0}\right.$, neglecting the trigonal distortion of Ru for clarity), Fig. 6b, shows two absorption peaks corresponding to the excitation from the $2 p$ orbital to the unoccupied $t_{2 \mathrm{~g}}$ and $e_{\mathrm{g}}$ orbitals. The peak position for the $2 p \rightarrow e_{\mathrm{g}}$ absorption $(2841.5 \mathrm{eV})$ is similar to that reported for $\mathrm{Ru}^{4+}(2841.6 \mathrm{eV})$ in $\mathrm{SrRuO}_{3}$ and $\mathrm{RuO}_{2}$ (ref. 27), confirming $\mathrm{Ru}^{4+}$ in pristine $\mathrm{O}-\mathrm{Na}_{2} \mathrm{RuO}_{3}$. On charging to ilmenite-type $\mathrm{Na}_{1} \mathrm{RuO}_{3}$, two absorption peaks shift to higher energy. Since the peak position of the $2 p \rightarrow e_{\mathrm{g}}$ absorption for ilmenite-type $\mathrm{Na}_{1} \mathrm{RuO}_{3}(2,843 \mathrm{eV})$ agrees with that of $\mathrm{Ru}^{5+}$ in $\mathrm{Sr}_{4} \mathrm{Ru}_{2} \mathrm{O}_{9}$ (ref. 27), oxidation from $\mathrm{Ru}^{4+}$ to $\mathrm{Ru}^{5+}$ occurs at the first potential plateau. However, further desodiation at the second plateau does not shift the $2 p \rightarrow e_{\mathrm{g}}$ absorption peak, suggesting no substantial change in the valence state of $\mathrm{Ru}$.

The $\mathrm{O} K$-edge spectrum of pristine $\mathrm{O}-\mathrm{Na}_{2} \mathrm{RuO}_{3}\left(t_{2 \mathrm{~g}}^{4} e_{\mathrm{g}}^{0}\right)$ shows a large peak at $534 \mathrm{eV}$, which is ascribed to the unoccupied hybridized orbital of $\mathrm{O} 2 p-\mathrm{Na} 3 p$, and its peak intensity simply reflects the amount of $\mathrm{Na}$ in the lattice ${ }^{30}$. The calculated density of states for $\mathrm{O}-\mathrm{Na}_{2} \mathrm{RuO}_{3}$ (Fig. 7a) also indicates that the
$\mathrm{O} 2 p-\mathrm{Na} 3 p$ hybridized orbital exists in this energy range. For the lower energy region that represents the redox reaction, the calculated oxygen $K$-edge spectrum agrees well with the spectra from 528 to $533 \mathrm{eV}$. Thus, the peaks around $529 \mathrm{eV}$ and $532 \mathrm{eV}$ can be ascribed to the unoccupied hybridized orbitals of $\mathrm{O}$ $2 p-\mathrm{Ru} t_{2 \mathrm{~g}}$ and $\mathrm{O} 2 p-\mathrm{Ru} e_{\mathrm{g}}$, respectively ${ }^{31,32}$. At the voltage plateau of $2.5 \mathrm{~V}$, desodiation diminishes the $\mathrm{O} 2 p-\mathrm{Na} 3 p$ signal, whereas the peak intensity of $\mathrm{O} 2 p-\mathrm{Ru} t_{2 \mathrm{~g}}$ (around $529 \mathrm{eV}$ ) increases on charging, indicating hole generation on the $\mathrm{O}$ $2 p-\mathrm{Ru} t_{2 \mathrm{~g}}$ orbital. The increase in the peak intensity around $529 \mathrm{eV}$ is also in good agreement with the calculated oxygen $K$-edge spectrum for ilmenite-type $\mathrm{Na}_{1} \mathrm{RuO}_{3}$.

On further charging at the second plateau (around 3.6 V), the peak intensity of the $\mathrm{O} 2 p-\mathrm{Ru} t_{2 \mathrm{~g}}$ is almost constant, whereas the peak around $532 \mathrm{eV}$ broadens as a result of the new absorption band emerging around $533 \mathrm{eV}$. This spectral change cannot be explained by $\mathrm{Ru}^{5+} \rightarrow \mathrm{Ru}^{6+}$ oxidation (hole generation on $\mathrm{O}$ $2 p-\mathrm{Ru} t_{2 \mathrm{~g}}$ ). One possible explanation is the formation of a new chemical bond involving oxygen. For example, formation of an $\mathrm{O}-\mathrm{O}$ bond (that is, peroxo/superoxo-like groups $\left.\mathrm{O}_{2}^{n-}(1 \leq n \leq 3)\right)$ has been proposed as the oxygen redox mechanism for many $\mathrm{Li}_{2}\left(\mathrm{M}, \mathrm{M}^{\prime}\right) \mathrm{O}_{3}$ cathode materials $\left(\mathrm{M}, \mathrm{M}^{\prime}=\right.$ $\mathrm{Fe}, \mathrm{Ru}, \mathrm{Sb}, \mathrm{Sn}$ or Ir) ${ }^{18,33,34}$. Here the hole generated by further 


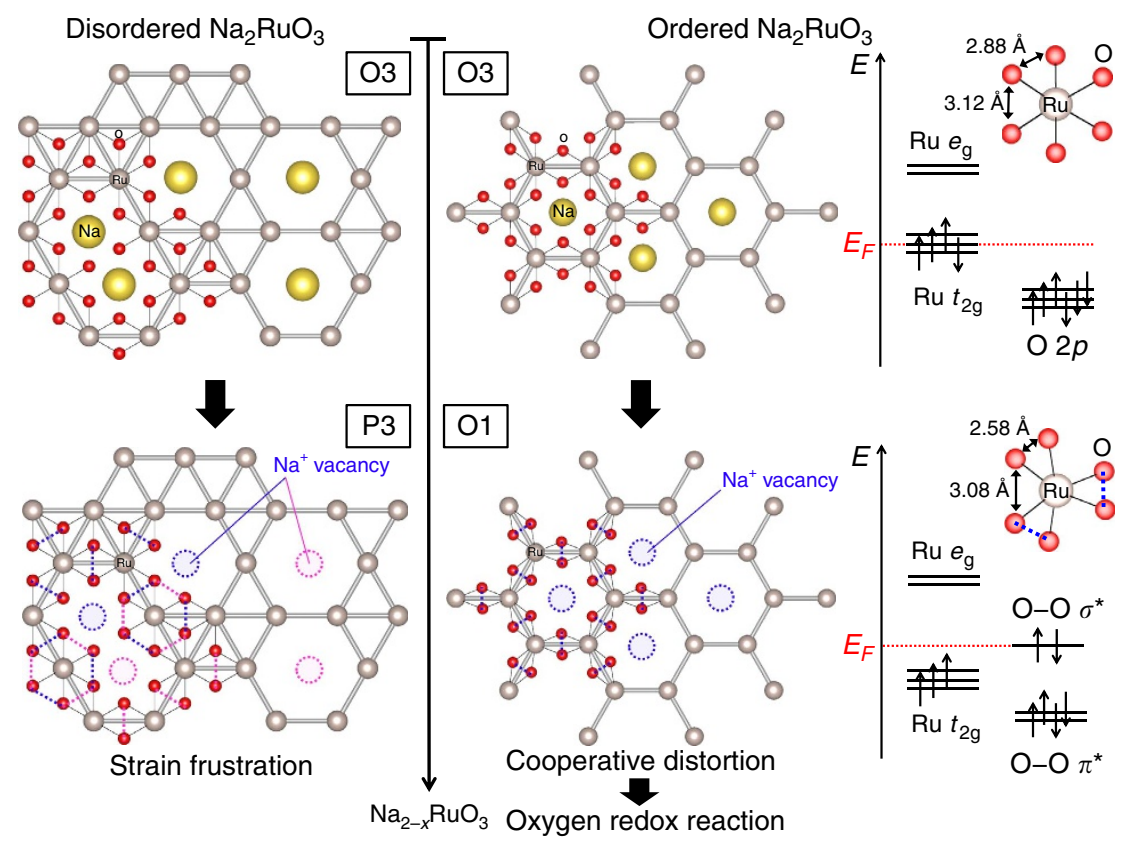

Figure 5 | Reaction mechanisms of disordered and ordered $\mathbf{N a}_{2} \mathbf{R u O}_{3}$. Schematic representation of the structural changes during charge-discharge for disordered $\mathrm{Na}_{2} \mathrm{RuO}_{3}$ and ordered $\mathrm{Na}_{2} \mathrm{RuO}_{3}$. Ordered $\mathrm{Na}_{2} \mathrm{RuO}_{3}$ can distort cooperatively to raise the energy level of the antibonding $\sigma^{\star}$ orbital of the $\mathrm{O}-\mathrm{O}$ bond, leading to the oxygen redox reaction. Disordered $\mathrm{Na}_{1} \mathrm{RuO}_{3}$ cannot accommodate the $\mathrm{RuO}_{6}$ distortion due to strain frustration, which prevents the oxygen redox reaction.

charging is stabilized on the antibonding $\sigma^{\star}$ orbital of the $\mathrm{O}-\mathrm{O}$ bond which is covalently bonded to the transition metal. It should be noted that the ${ }^{99} \mathrm{Ru}$ Mössbauer spectrum of $\mathrm{O}-\mathrm{Na}_{0.62} \mathrm{RuO}_{3}$ (Supplementary Fig. 8) shows absorption with an isomer shift of $\delta=+0.21 \mathrm{mms}^{-1}$, which is a typical value for $\mathrm{Ru}^{5+}$ $\left(+0.11 \mathrm{~mm} \mathrm{~s}^{-1}\right.$ for $\mathrm{Na}_{3} \mathrm{RuO}_{4}$ and $+0.19 \mathrm{~mm} \mathrm{~s}^{-1}$ for $\left.\mathrm{Ca}_{2} \mathrm{EuRuO}_{6}\right)^{22}$, supporting that no further $\mathrm{Ru}^{5+} \rightarrow \mathrm{Ru}^{6+}$ oxidation occurs.

On discharge, while the $2 p \rightarrow t_{2 \mathrm{~g}}$ and $2 p \rightarrow e_{\mathrm{g}}$ signals in the $\mathrm{Ru}$ $L_{3}$-edge spectra shift to the initial lower energy region, the $\mathrm{O}-\mathrm{O}$ bond and $\mathrm{O} 2 p-\mathrm{Ru} t_{2 \mathrm{~g}}$ signals in the $\mathrm{O} K$-edge spectra decrease reversibly (Supplementary Figs 6 and 7). Furthermore, although the diffraction peaks of the ex situ XRD pattern after cycling exhibit weak broadening due to the slight loss of the crystallinity, $\mathrm{O}-\mathrm{Na}_{2} \mathrm{RuO}_{3}$ still shows characteristic diffuse scatterings similar to the pristine compound (Supplementary Fig. 1b), which suggests that the honeycomb-type in-plane ordering is maintained during the charge-discharge cycles for all $\mathrm{Na}$ compositions, where $0.7 \leq x \leq 2$. Importantly, this is the first simultaneous achievement of extra oxygen redox capacity and structural integrity leading to totally reversible oxygen participation. All other $A_{2}-{ }_{x} \mathrm{MO}_{3}$-type electrodes suffer from severe structural rearrangement on the first charge and from lowering of the operating voltage during subsequent cycles ${ }^{16,17,34-36}$. This structural rearrangement occurs because $M$ migrates from octahedral sites in the $M$ layer to facesharing tetrahedral sites in the adjacent $A$ layer ${ }^{35}$. Presumably, this inter-site migration of $\mathrm{Ru}$ is suppressed in $\mathrm{Na}_{2} \mathrm{RuO}_{3}$ because of incompatibility of large $\mathrm{Ru}$ with the tetrahedral site. Furthermore, the interlayer $\mathrm{O}-\mathrm{O}$ bond formation, which is predicted theoretically for delithiated $\mathrm{Li}_{2} \mathrm{MnO}_{3}$ to destabilize the oxygen redox reaction ${ }^{37}$, should be inhibited by the large interlayer distance in $\mathrm{Na}_{x} \mathrm{RuO}_{3}$ (for example, 5.2-5.5 $\mathrm{\AA}$ for $\mathrm{Na}_{x} \mathrm{RuO}_{3}$ and $4.7-4.8 \AA$ for $\left.\mathrm{Li}_{x} \mathrm{Ru}_{0.75} \mathrm{Mn}_{0.25} \mathrm{O}_{3}\right)^{36}$. As shown in Supplementary Fig. 9, the initial Coulombic efficiency of $\mathrm{O}-\mathrm{Na}_{2} \mathrm{RuO}_{3}$ is higher (95\%) than that of other $A_{2-}{ }_{x} \mathrm{MO}_{3}$ (for example, $70 \%$ for $\mathrm{Li}_{2} \mathrm{MnO}_{3}$ and $90 \%$ for $\left.\mathrm{Li}_{2} \mathrm{RuO}_{3}\right)^{17,36,38,39}$.

\section{Discussion}

The critical role of honeycomb ordering in $\mathrm{Na}_{2} \mathrm{RuO}_{3}$ based on the aforementioned original observations is summarized in Fig. 5. The ordered $\left[\square_{1 / 3} \mathrm{Ru}_{2 / 3}\right] \mathrm{O}_{2}$ slabs in ilmenite $\mathrm{O}-\mathrm{Na}_{1} \mathrm{RuO}_{3}$ accommodate the distortion of the $\mathrm{RuO}_{6}$ octahedra cooperatively, whereby the shortest $\mathrm{O}-\mathrm{O}$ distance is $2.580(4) \AA$. Because the short $\mathrm{O}-\mathrm{O}$ distance raises the energy level of the antibonding $\sigma^{\star}$ orbital of the O-O bond to the Fermi level, the oxygen redox reaction is triggered. Indeed, the calculated density of states for ilmenite $\mathrm{O}-\mathrm{Na}_{1} \mathrm{RuO}_{3}$ (Fig. 7b) shows that the occupied antibonding orbitals of the $\mathrm{O}-\mathrm{O}$ bond exist near the Fermi level. The naturally derived scenario is that, once the hole is generated on the antibonding $\sigma^{*}$ orbital of the $\mathrm{O}-\mathrm{O}$ bond, the $\mathrm{O}-\mathrm{O}$ distance becomes shorter ${ }^{40}$. This short distance leads to the higher energy level of the antibonding $\sigma^{*}$ orbital of the oxygen-oxygen bond and an acceleration of the oxygen redox reaction. This hypothesis was recently reinforced by McCalla et al. ${ }^{34}$ : scanning transmission electron microscopy and neutron diffraction on fully delithiated $\mathrm{Li}_{2} \mathrm{IrO}_{3}\left(\mathrm{Li}_{0.5} \mathrm{IrO}_{3}\right)$ determined the shorter O-O distance $(2.45 \AA)$ after the oxygen oxidation. However, as demonstrated in this work, the short $\mathrm{O}-\mathrm{O}$ distance is required before the oxygen oxidation to achieve the extra capacity. For example, the disordered $\left[\mathrm{Na}_{1 / 3} \mathrm{Ru}_{2 / 3}\right] \mathrm{O}_{2}$ slabs in $\mathrm{D}-\mathrm{Na}_{1} \mathrm{RuO}_{3}$ cannot accommodate the cooperative distortion of the $\mathrm{RuO}_{6}$ octahedra owing to strain frustration. Thus, the $\mathrm{O}-\mathrm{O}$ distances in $\mathrm{D}-\mathrm{Na}_{1} \mathrm{RuO}_{3}$ are long enough (2.751(6) and 2.927(1) $\AA$ ) so that the energy level of the antibonding $\sigma^{\star}$ orbital of the $\mathrm{O}-\mathrm{O}$ bond is well below the Fermi level, which inhibits the extra oxygen redox process within the electrolyte stability window. Therefore, honeycomb-type cation ordering in the $\left[\mathrm{Na}_{1 / 3} \mathrm{M}_{2 / 3}\right] \mathrm{O}_{2}$ slab is a structural requisite condition to trigger the stable oxygen redox capacity in $\mathrm{Na}_{2} \mathrm{MO}_{3}$.

Finally, we mention the role of $\mathrm{Ru}$ in the oxygen redox reaction. Very recently, Saubanère et al. ${ }^{37}$ theoretically demonstrated that the covalent bond between the peroxo-like $\left(\mathrm{O}_{2}\right)^{n-} 2 p$ and $\mathrm{Ru} 4 d$ orbitals in $\mathrm{Li}_{2} \mathrm{RuO}_{3}$ (reductive coupling 


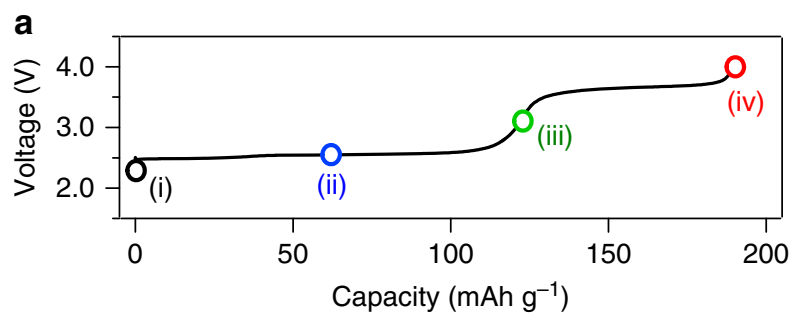

b

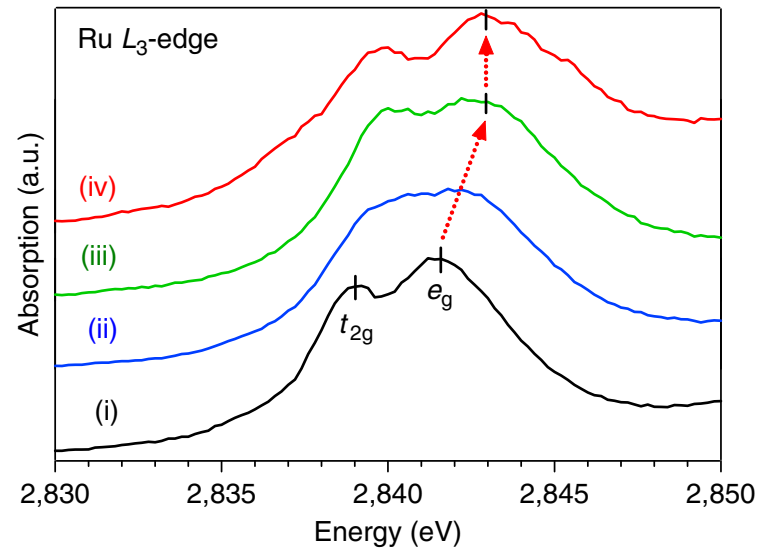

C

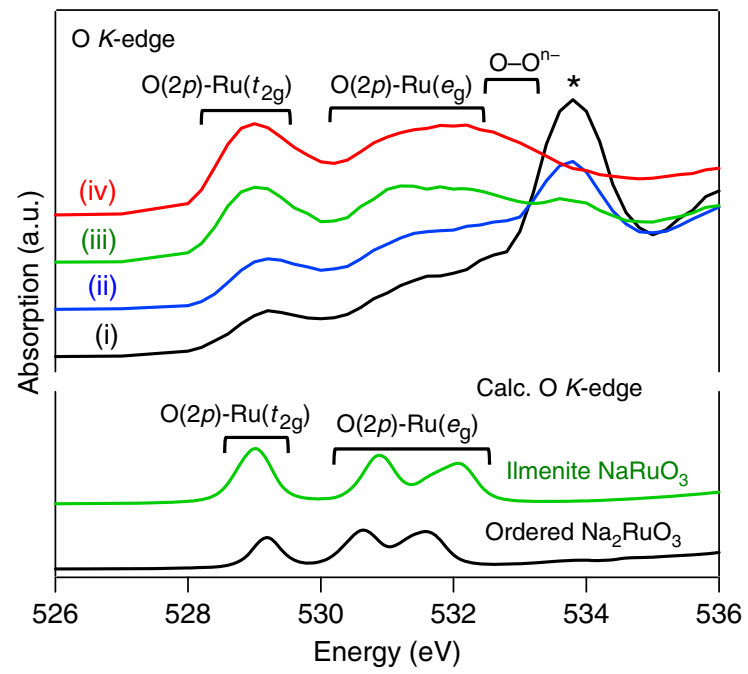

Figure 6 | Electronic structure changes of ordered $\mathrm{Na}_{2} \mathrm{RuO}_{3}$ upon charge. (a) States of charge of the samples for X-ray absorption spectroscopy.

(b) Ruthenium $L_{3}$-edge and (c) oxygen $K$-edge $X$-ray absorption spectra for various $\mathrm{O}-\mathrm{Na}_{x} \mathrm{RuO}_{3}$ compositions: (i) $x=2.0$ (black), (ii) $x=1.5$ (blue), (iii) $x=1.0$ (green) and (iv) $x=0.62$ (red). The asterisked peak corresponds to $\mathrm{O} 2 p-\mathrm{Na} 3 p$. The calculated oxygen $\mathrm{K}$-edge spectra for ordered $\mathrm{Na}_{2} \mathrm{RuO}_{3}$ (black) and ilmenite-type $\mathrm{NaRuO}_{3}$ (green) are also shown.

mechanism) is essential to facilitate the oxygen redox reaction and to suppress the oxygen gas release, whereas the $\mathrm{M}(3 \mathrm{~d})-\mathrm{O}(2 p)$ overlap is too small to enable this mechanism. For $\mathrm{O}-\mathrm{Na}_{2} \mathrm{RuO}_{3}$, in addition to the stable structural nature inherent in the $\mathrm{Na}$ system by suppressing both the inter-site Ru migration and the interlayer $\mathrm{O}-\mathrm{O}$ bond formation as discussed above, the similar reductive coupling mechanism through the large orbital overlap between the $\mathrm{Ru} 4 d$ and $\mathrm{O} 2 p$ orbitals should suppress the oxygen gas release, which explains the high cycle stability of $\mathrm{O}-\mathrm{Na}_{2} \mathrm{RuO}_{3}$ compared with that of any other $\mathrm{Li}$ excess materials (Supplementary Fig. 9).
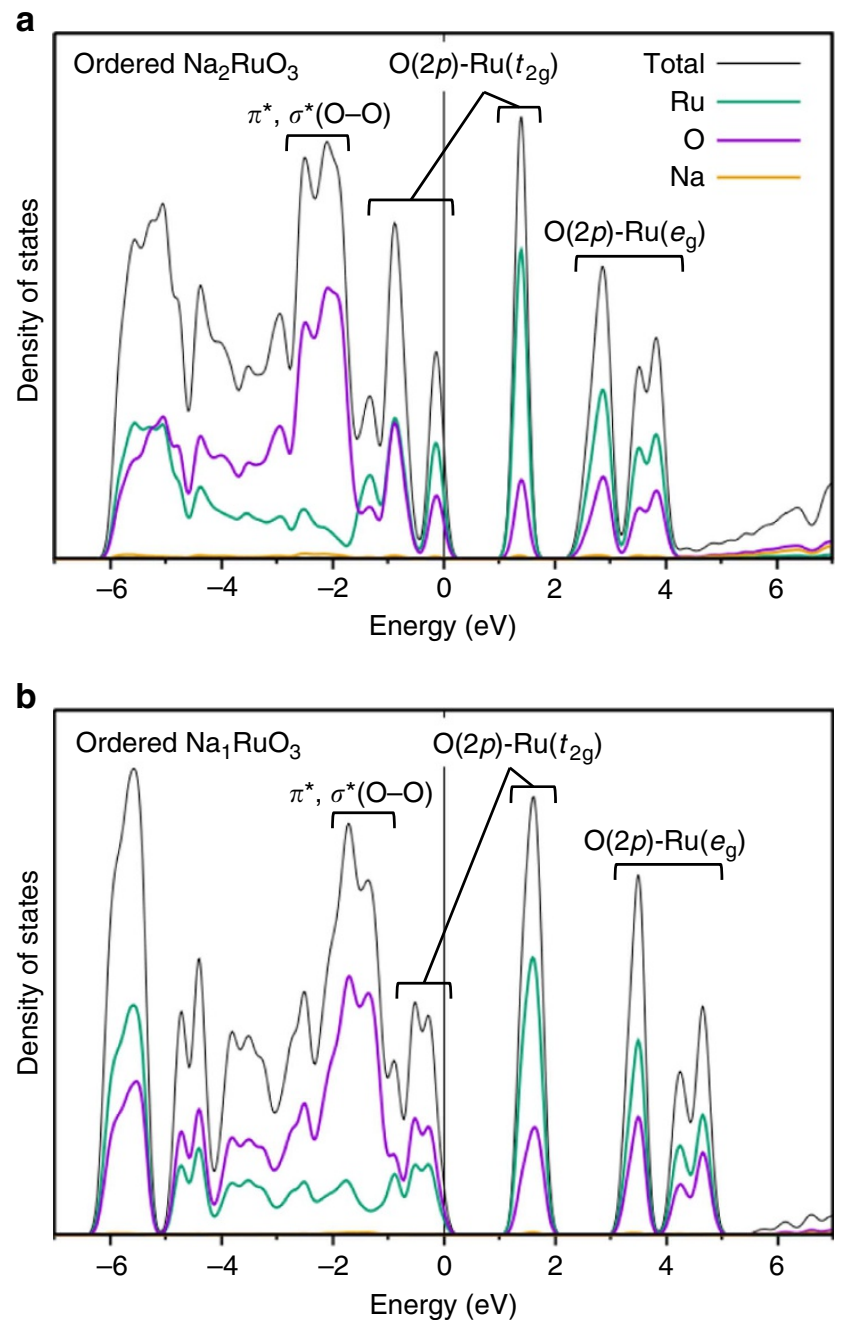

Figure 7 | Calculated electronic structure of ordered $\mathrm{Na}_{2} \mathrm{RuO}_{3}$ upon

charge. Calculated density of states (DOS) for ordered (a) $\mathrm{O}_{3}-\mathrm{Na}_{2} \mathrm{RuO}_{3}$ and (b) ilmenite-type $\mathrm{Na}_{1} \mathrm{RuO}_{3}$.

In conclusion, the present work demonstrates the critical role of honeycomb-type cation ordering in $\mathrm{Na}_{2} \mathrm{MO}_{3}$ to achieve enhanced reversible capacity based on the oxygen redox process. In comparison to its disordered polymorph, $\mathrm{O}-\mathrm{Na}_{2} \mathrm{RuO}_{3}$ with inplane honeycomb ordering exhibits a significantly different voltage profile, leading to a $30 \%$ extra capacity, spurred by the electrochemically driven, further ordered intermediate, $\mathrm{NaRuO}_{3}$, which accommodates cooperative distortion of the $\mathrm{RuO}_{6}$ octahedra. The short $\mathrm{O}-\mathrm{O}$ distance in distorted $\mathrm{RuO}_{6}$ induces frontier orbital reorganization, triggering the oxygen redox reaction.

To the best of our knowledge, this is the first report that clarifies the underlying structural requirement to trigger the oxygen redox reaction in $A_{2-x} \mathrm{MO}_{3}$. By further exploiting the compositional versatility of $A_{2} \mathrm{MO}_{3}$ while meeting this requirement, there is great potential to develop oxygen redox electrodes for superior batteries. Considering the impact of the stable intermediate on the overall electrode properties, the peculiar phenomena and concepts demonstrated here may give general implications for a deeper understanding and improved utilization of intercalation materials.

\section{Methods}

Synthesis of $\mathbf{N a}_{\mathbf{2}} \mathbf{R u O}_{\mathbf{3}}$. Ordered $\mathrm{Na}_{2} \mathrm{RuO}_{3}$ was synthesized by the thermal decomposition method according to the literature where $\mathrm{Na}_{2} \mathrm{RuO}_{4}$ was annealed at 
$850{ }^{\circ} \mathrm{C}$ for $48 \mathrm{~h}$ under $\mathrm{Ar}$ atmosphere ${ }^{21}$. Disordered $\mathrm{Na}_{2} \mathrm{RuO}_{3}$ was synthesized according to the procedure we previously reported ${ }^{19}$. The $\mathrm{NaHCO}_{3}$ and $\mathrm{RuO}_{2}$ precursors were calcined at $850^{\circ} \mathrm{C}$ for $12 \mathrm{~h}$ under Ar atmosphere. Both compounds were handled in a globe box filled with $\mathrm{Ar}\left(\mathrm{dew}\right.$ point below $\left.-110^{\circ} \mathrm{C}\right)$

Materials characterization. Powder X-ray diffraction patterns were recorded on a Rigaku TTR-III diffractometer equipped with $\mathrm{Cu} K \alpha$ radiation in $0.02^{\circ}$ steps over the $2 \theta$ range of $10-80^{\circ}$. XRD patterns were measured at SPring-8 BL02B2 and Photon Factory BL-8B. The samples were handled without air exposure throughout the experiments. Rietveld refinements were carried out using Jana2006 (ref. 41) or TOPAS-Academic software. The profile of $\mathrm{Na}_{1} \mathrm{RuO}_{3}$ was better described using independent crystallite size for $00 l$ reflections, Popa's sphere harmonics for $h 0 l$ and $h k l$ reflections and different crystallite sizes for $(h 0 k)=3 n$ as implemented in TOPAS in order to take into account the stacking faults affecting part of the diffraction peaks. The crystal structures were drawn using VESTA ${ }^{42}$. SAED patterns were recorded using an electron microscope (HF-3000S; Hitachi Ltd.) operated at $300 \mathrm{kV}$ and an imaging plate system (FDL-5000; Fujifilm). The camera length was calibrated with a $\mathrm{Si}$ crystal. ${ }^{99} \mathrm{Ru}$ Mössbauer spectroscopy was carried out with the ${ }^{99} \mathrm{Rh}$ source $\left(T_{1 / 2}=15\right.$ days), which was prepared by the ${ }^{99} \mathrm{Ru}(\mathrm{p}, \mathrm{n}){ }^{99} \mathrm{Rh}$ reaction at the RIKEN AVF cyclotron. The ${ }^{99} \mathrm{Ru}(\mathrm{p}, \mathrm{n}){ }^{99} \mathrm{Rh}$ reaction was conducted with a ${ }^{99} \mathrm{Ru}$ (95\% enriched) target under $12 \mathrm{MeV}$ proton irradiation. Both the source and the samples were cooled in liquid He during the measurements. The samples were transferred into the liquid $\mathrm{He}$ cryostat without air exposure. The Doppler velocity was calibrated by measuring a ${ }^{57} \mathrm{Fe}$ Mossbauer spectrum of $\alpha-\mathrm{Fe}$, and the zero velocity was determined by the isomer shift of $\mathrm{Ru}$ metal at $4.2 \mathrm{~K}$.

Electrochemical measurement. For the electrochemical measurements, $80 \mathrm{wt} \%$ of $\mathrm{Na}_{2} \mathrm{RuO}_{3}$ was mixed with $10 \mathrm{wt} \%$ of acetylene black and $10 \mathrm{wt} \%$ of polyvinylidene in $N$-methyl pyrrolidone to make a slurry, which was then coated onto $\mathrm{Al}$ foil. The dried films were used as a cathode in the 2,032-type coin cells with Na metal as an anode. $\mathrm{NaPF}_{6}(1 \mathrm{M})$ in ethylene carbonate/diethyl carbonate $(1: 1 \mathrm{v} / \mathrm{v})$ was used as an electrolyte. The charge-discharge experiments were conducted at $30 \mathrm{mAg}^{-1}$ between $1.5-4.0 \mathrm{~V}$ versus $\mathrm{Na} / \mathrm{Na}^{+}$, within the electrolyte stability window.

Samples for ex situ characterization. The electrodes for ex situ XRD, XAS and ${ }^{99} \mathrm{Ru}$ Mossbauer spectroscopy were prepared as described above. O- $\mathrm{Na}_{1} \mathrm{RuO}_{3}$ samples for synchrotron XRD and TEM studies were prepared following the same method except that the positive electrode consisted in a pellet $(\varnothing 10 \mathrm{~mm}, 50 \mathrm{mg})$ of $\mathrm{O}-\mathrm{Na}_{2} \mathrm{RuO}_{3}$ that was sintered at $850^{\circ} \mathrm{C}$ for $12 \mathrm{~h}$. The batteries were then cycled to a designated voltage that was maintained for a few hours $\left(\mathrm{Na}_{1} \mathrm{RuO}_{3}\right)$ or until a given current has been applied. After cycling, the batteries were introduced into an Ar-filled glovebox and the collected electrodes were washed three to five times with anhydrous dimethyl carbonate.

In situ XRD. In situ XRD (operando mode) was carried out using an in situ cell purchased from Rigaku on a D8 ADVANCE powder diffractometer equipped with Co $K \alpha$ radiation in $0.02^{\circ}$ steps over the $2 \theta$ range of $17-25^{\circ}$ ( $1.37 \mathrm{~s}$ per step, one pattern recorded every $\approx 12 \mathrm{~min}$ ). The electrochemical part of the cell is similar to the one described above. The only exception lies in the preparation of the electrode whose slurry was coated on plastic films to be peeled off after drying. The current rate was C/20 (full (dis)charge theoretically achieved in $20 \mathrm{~h}$ ), allowing us to record an XRD pattern every $\Delta x=0.02$. Only selected patterns are shown in Supplementary Fig. 4 for clarity concerns. Electrochemistry was controlled and recorded using a Biologic VMP3.

X-ray absorption. O K-edge XAS was carried out at BL07LSU of SPring-8. The samples were transferred to a vacuum chamber without air exposure. Bulk-sensitive partial-fluorescence yield (PFY) mode was used for the O K-edge XAS. Energy resolution was approximately $100 \mathrm{meV}$. All the spectra were recorded using a silicon drift detector at room temperature. The spectra were normalized by the peak intensity at $532 \mathrm{eV}$, because the peak at $532 \mathrm{eV}$ corresponding to $\mathrm{O} 2 p-\mathrm{Ru} e_{\mathrm{g}}$ may not be affected by the redox of $\mathrm{Ru}^{5+} / \mathrm{Ru}^{4+}$. $\mathrm{Ru} L_{3}$-edge XAS was carried out at BL27SU of SPring-8. The samples were transferred to a vacuum chamber without exposure to air. The spectra were recorded in the bulk-sensitive PFY mode using a silicon drift detector at room temperature.

$\boldsymbol{A} \boldsymbol{b}$ initio calculation. Spin-polarized DFT $+U$ calculations were performed using the VASP code ${ }^{43}$ with $U_{\text {eff }}$ for Ru ranging from 0.5 to $4.5 \mathrm{eV}$. Van der Waals density functional optPBE ${ }^{4}$ was employed. The plane-wave energy cut-off was set to $520 \mathrm{eV}$ and the Brillouin zone integration was done in a k-point grid chosen to converge the energy to $10^{-4} \mathrm{eV}$. Atomic coordinates and lattice parameters were relaxed using conjugate gradient method until the maximum force on atoms is $<2 \times 10^{-3} \mathrm{eV} \AA^{-1}$. Initial geometry of $\mathrm{Na}_{2} \mathrm{RuO}_{3}$ in the $\mathrm{C} 2 / \mathrm{m}$ symmetry was taken from the literature ${ }^{45}$ while the initial geometry for $\mathrm{NaRuO}_{3}$ in the $R \overline{3}$ symmetry is from the present work. Antiferromagnetic ordering of spin on Ru was assumed, the pattern was set to be Néel type. The oxygen K-edge X-ray absorption pattern was calculated by the WIEN2k code ${ }^{46}$ employing the full potential linear augmented plane-wave method, dipole approximation to the golden rule for the transition probability was assumed.

\section{References}

1. Yabuuchi, N., Kubota, K., Dahbi, M. \& Komaba, S. Research development on sodium-ion batteries. Chem. Rev. 114, 11636-11682 (2014).

2. Kundu, D., Talaie, E., Duffort, V. \& Nazar, L. F. The emerging chemistry of sodium ion batteries for electrochemical energy storage. Angew. Chem. Int. Ed. 54, 3431-3448 (2015).

3. Yabuuchi, N. et al. P2-type $\mathrm{Na}_{x}\left[\mathrm{Fe}_{1 / 2} \mathrm{Mn}_{1 / 2}\right] \mathrm{O}_{2}$ made from earthabundant elements for rechargeable Na batteries. Nat. Mater. 11, 512-517 (2012).

4. Barpanda, P., Oyama, G., Nishimura, S., Chung, S. C. \& Yamada, A. A 3.8 V Earth-abundant sodium battery electrode. Nat. Commun. 5, 4358 (2014).

5. Billaud, J. et al. $\beta-\mathrm{NaMnO}_{2}$ : a high-performance cathode for sodium-ion batteries. J. Am. Chem. Soc. 136, 17243-17248 (2014).

6. Wang, X. et al. Pseudocapacitance of MXene nanosheets for high-power sodium-ion hybrid capacitors. Nat. Commun. 6, 6544 (2015).

7. Qian, J., Wu, X., Cao, Y., Ai, X. \& Yang, H. High capacity and rate capability of amorphous phosphorous for sodium-ion batteries. Angew. Chem. Int. Ed. 52, 4633-4636 (2013).

8. Wang, Y. et al. A zero-strain layered metal oxide as the negative electrode for long-life sodium-ion batteries. Nat. Commun. 3, 2365 (2013).

9. Komaba, S. et al. Study on the reversible electrode reaction of $\mathrm{Na}_{1-x} \mathrm{Ni}_{0.5} \mathrm{Mn}_{0.5} \mathrm{O}_{2}$ for a rechargeable sodium-ion battery. Inorg. Chem. $\mathbf{5 1}$, 6211-6220 (2012).

10. Wang, X., Liu, G., Iwao, T., Okubo, M. \& Yamada, A. Role of ligand-to-metal charge transfer in O3-Type $\mathrm{NaFeO}_{2}-\mathrm{NaNiO}_{2}$ solid solution for enhanced electrochemical properties. J. Phys. Chem. C 118, 2970-2976 (2014).

11. Mortemard de Boisse, B., Carlier, D., Guignard, M., Bourgeois, L. \& Delmas, C. $\mathrm{P} 2-\mathrm{Na}_{x} \mathrm{Mn}_{1 / 2} \mathrm{Fe}_{1 / 2} \mathrm{O}_{2}$ phase used as positive electrode in Na Batteries; structural changes induced by the electrochemical (De)intercalation process. Inorg. Chem. 53, 11197-11205 (2014).

12. Li, X. et al. Direct visualization of the Jahn-Teller effect coupled to Na ordering in $\mathrm{Na}_{5 / 8} \mathrm{MnO}_{2}$. Nat. Mater. 13, 586-592 (2014).

13. Billaud, J. et al. $\mathrm{Na}_{0.67} \mathrm{Mn}_{1-x} \mathrm{Mg}_{x} \mathrm{O}_{2}(0 \leq x \leq 0.2)$ : a high capacity cathode for sodium-ion batteries. Energy Environ. Sci. 7, 1387-1391 (2014).

14. Ma, X., Chen, H. \& Ceder, G. Electrochemical properties of monoclinic $\mathrm{NaMnO}_{2}$. J. Electrochem. Soc. 158, A1307-A1312 (2015).

15. Yabuuchi, N., Yano, M., Yoshida, H., Kuze, S. \& Komaba, S. Synthesis and electrode performance of O3-type $\mathrm{NaFeO}_{2}-\mathrm{NaNi}_{1 / 2} \mathrm{Mn}_{1 / 2} \mathrm{O}_{2}$ solid solution for rechargeable sodium batteries. J. Electrochem. Soc. 160, A3131-A3137 (2013).

16. Thackeray, M. M., Johnson, C. S., Vaughey, J. T., Li, N. \& Hackney, S. A. Advances in manganese-oxide 'composite' electrodes for lithium-ion batteries. J. Mater. Chem. 15, 2257-2267 (2005).

17. Sathiya, M. et al. Reversible anionic redox chemistry in high-capacity layeredoxide electrodes. Nat. Mater. 12, 827-835 (2013)

18. Sathiya, M. et al. Electron paramagnetic resonance imaging for real time monitoring of Li-ion batteries. Nat. Commun. 6, 6276 (2015).

19. Tamaru, M., Wang, X., Okubo, M. \& Yamada, A. Layered $\mathrm{Na}_{2} \mathrm{RuO}_{3}$ as a cathode material for $\mathrm{Na}$-ion batteries. Electrochem. Commun. 33, 23-26 (2013).

20. Rozier, P. et al. Anionic redox chemistry in Na-rich $\mathrm{Na}_{2} \mathrm{Ru}_{1-y} \mathrm{Sn}_{y} \mathrm{O}_{3}$ positive electrode materials for Na-ion batteries. Electrochem. Commun. 53, 29-32 (2015).

21. Mogare, K. M., Friese, K., Klein, W. \& Jansen, M. Synthesis and crystal structures of two sodium ruthenate: $\mathrm{Na}_{2} \mathrm{RuO}_{4}$ and $\mathrm{Na}_{2} \mathrm{RuO}_{3}$. Z. Anorg. Chem 630, 547-552 (2004).

22. Gütlich, P., Bill, E. \& Trautwein, A. X. in Mössbauer Spectroscopy and Transition Metal Chemistry (Springer-Verlag, 2011).

23. Delmas, C., Fouassier, C. \& Hagenmuller, P. Structural classification and properties of the layered oxides. Phys. B 99, 81-85 (1980).

24. Meng, Y. S. et al. Cation ordering in layered O3 $\mathrm{Li}\left[\mathrm{Ni}_{x} \mathrm{Li}_{1 / 3-2 x / 3} \mathrm{Mn}_{2 / 3}-x / 3\right] \mathrm{O}_{2}$ $(0 \leq x \leq 1 / 2)$ compounds. Chem. Mater. 17, 2386-2394 (2005).

25. Mortemard de Boisse, B. et al. $\mathrm{O} 3-\mathrm{Na}_{x} \mathrm{Mn}_{1 / 3} \mathrm{Fe}_{2 / 3} \mathrm{O}_{2}$ as a positive electrode materials for $\mathrm{Na}$-ion batteries: structural evolutions and redox mechanisms upon $\mathrm{Na}^{+}$(de)intercalation. J. Mater. Chem. A 3, 10976-10989 (2015).

26. Barth, T. F. W. \& Posnjak, E. The crystal structure of ilmenite. Z. Kristallogr. 88, 265-270 (1934)

27. Manoharan, S. S. \& Sahu, R. K. Evidence for an anomalous redox ionic pair between $\mathrm{Ru}$ and $\mathrm{Mn}$ in $\mathrm{SrRu}_{0.5} \mathrm{Mn}_{0.5} \mathrm{O}_{3}$ : an X-ray absorption spectroscopy approach. Chem. Commun. 21, 3068-3069 (2002).

28. de Groot, F. \& Kotani, A. Core Level Spectroscopy of Solids; Advances in Condensed Matter Science (CRC Press, 2008).

29. Achkar, A. J. et al. Bulk sensitive X-ray absorption spectroscopy free of selfabsorption effects. Phys. Rev. B 83, 081106 (R) (2011). 
30. Kroll, T. et al. X-ray absorption spectroscopy of $\mathrm{Na}_{x} \mathrm{CoO}_{2}$ layered cobaltates. Phys. Rev. B 74, 115123 (2006).

31. Han, S. W. et al. Electronic structure of $\mathrm{RuSr}_{2} \mathrm{EuCu}_{2} \mathrm{O}_{8}$ studied by $\mathrm{X}$-ray absorption and photoemission spectroscopies. Phys. Rev. B 85, 014506 (2012).

32. Pchelkina, Z. V. et al. Electronic structure of $\mathrm{Li}_{2} \mathrm{RuO}_{3}$ studied by $\mathrm{LDA}$ and LDA + DMFT calculations and soft X-ray spectroscopy. Phys. Rev. B 91, 115138 (2015)

33. McCalla, E. et al. Understanding the roles of anionic redox and oxygen release during electrochemical cycling of lithium-rich layered $\mathrm{Li}_{4} \mathrm{FeSbO}_{6}$. J. Am. Chem. Soc. 137, 4804-4814 (2015).

34. McCalla, E. et al. Visualization of O-O peroxo-like dimers in high-capacity layered oxides for Li-ion batteries. Science 350, 1516-1521 (2015).

35. Sathiya, M. et al. Origin of voltage decay in high-capacity layered oxide electrodes. Nat. Mater. 14, 230-238 (2015).

36. Sathiya, M. et al. High performance $\mathrm{Li}_{2} \mathrm{Ru}_{1-y} \mathrm{Mn}_{y} \mathrm{O}_{3}(0.2 \leq x \leq 0.8)$ cathode materials for rechargeable lithium-ion batteries: their understanding. Chem. Mater. 25, 1121-1131 (2013).

37. Saubanère et al. The intriguing question of anionic redox in highenergy density cathodes for Li-ion batteries. Energy Environ. Sci. 9, 984-991 (2016).

38. Yu, D. Y. W., Tanagida, K., Kato, Y. \& Nakamura, H. Electrochemical activities in $\mathrm{Li}_{2} \mathrm{MnO}_{3}$. J. Electrochem. Soc. 156, A417-A424 (2009).

39. Koga, H. et al. Different oxygen redox participation for bulk and surface: a possible global explanation for the cycling mechanism of $\mathrm{Li}_{1.20} \mathrm{Mn}_{0.54} \mathrm{Co}_{0.13} \mathrm{Ni}_{0.13} \mathrm{O}_{2}$. J. Power Sources 236, 250-258 (2013).

40. Tarascon, J. M. et al. In situ structural and electrochemical study of $\mathrm{Ni}_{1-x} \mathrm{Co}_{x} \mathrm{O}_{2}$ metastable oxides prepared by soft chemistry. J. Solid State Chem. 147, 410-420 (1999).

41. Petřiček, V., Dušek, M. \& Palatinus, L. Jana2006-the crystallographic computing system: General features. Z. Kristallogr. 229, 345-352 (2014).

42. Monma, K. \& Izumi, F. VESTA 3 for Three-dimensional visualization of crystal, volumetric and morphology data. J. Appl. Cryst. 44, 1272-1276 (2011).

43. Kresse, G. \& Furthmüller, J. Efficiency of ab-initio total energy calculations for metals and semiconductors using a plane-wave basis set. Comput. Mat. Sci. 6, 15-50 (1996).

44. Klimes, J., Bowler, D. R. \& Michaelides, A. Chemical accuracy for the van der waals density functional. J. Phys. Condens. Matter 22, 022201 (2010).

45. Wang, J. C. et al. Lattice-tuned magnetism of $\mathrm{Ru}^{4+}\left(4 \mathrm{~d}^{4}\right)$ ions in single crystals of tshe layered honeycomb ruthenates $\mathrm{Li}_{2} \mathrm{RuO}_{3}$ and $\mathrm{Na}_{2} \mathrm{RuO}_{3}$. Phys. Rev. B 90, 161110 (2014)

46. Blaha, P., Schwarz, K., Madsen, G., Kvasnicka, D. \& Luitz, J. WIEN2k, An Augmented Plane Wave + Local Orbitals Program for Calculating Crystal Properties (Karlheinz Schwarz, Techn. Univ. Wien, Austria, 2001).

\section{Acknowledgements}

This work was financially supported by the Ministry of Education, Culture, Sports, Science and Technology (MEXT), Japan; Grant-in-Aid for Specially Promoted Research No. 15H05701. This work was also supported by MEXT, Japan under the 'Elemental Strategy Initiative for Catalysis and Batteries (ESICB)'. M.O. was financially supported by MEXT, Japan; Grant-in-Aid for Challenging Exploratory Research No. 15K13798. M.O was also supported by the Hattori Hokokai Foundation. The synchrotron XRD experiment was performed under approval of Photon Factory Program Advisory Committee (Proposal No.2013G670) and the Japan Synchrotron Radiation Research Institute (JASRI) (Proposal No. 2015A1503, 2014A1196 and 2013A1665). The SAED patterns were recorded at Nanotechnology Platform of MEXT (No. A-14-NM-0064). The synchrotron X-ray absorption experiments at SPring-8 were performed with the approval of the Japan Synchrotron Radiation Research Institute (Proposal No. 2015B1471) and by the joint research in the Synchrotron Radiation Research Organization and the Institute for Solid State Physics, the University of Tokyo (Proposal No. 2015A7403).

\section{Author contributions}

M.O. and A.Y. conceived and directed the project. B.M.d.B., G.L. and J.M. synthesized $\mathrm{Na}_{2} \mathrm{RuO}_{3}$. B.M.d.B., G.L. and J.M. evaluated the electrochemical properties of $\mathrm{Na}_{2} \mathrm{RuO}_{3}$ B.M.d.B., G.L. and S.N. analysed the XRD patterns of $\mathrm{Na}_{x} \mathrm{RuO}_{3}$. M.O., H.K. and Y.H. measured and analysed the XAS spectra. J.K. measured and analysed the TEM and electron diffraction micrographs. Y.K. measured and analysed the ${ }^{99} \mathrm{Ru}$ Mössbauer spectra. S.-C.C calculated the oxygen K-edge spectra and the density of states. B.M.d.B., S.N., M.O. and A.Y. wrote the manuscript. All authors commented on the manuscript.

\section{Additional information}

Supplementary Information accompanies this paper at http://www.nature.com/ naturecommunications

Competing financial interests: The authors declare no competing financial interests.

Reprints and permission information is available online at http://npg.nature.com/ reprintsandpermissions/

How to cite this article: Mortemard de Boisse, B. et al. Intermediate honeycomb ordering to trigger oxygen redox chemistry in layered battery electrode. Nat. Commun. 7:11397 doi: 10.1038/ncomms11397 (2016).

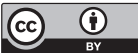

This work is licensed under a Creative Commons Attribution 4.0 International License. The images or other third party material in this article are included in the article's Creative Commons license, unless indicated otherwise in the credit line; if the material is not included under the Creative Commons license, users will need to obtain permission from the license holder to reproduce the material. To view a copy of this license, visit http://creativecommons.org/licenses/by/4.0/ 